\title{
Morphometric Study of a Horseshoe Kidney
}

\author{
Hale Oktem ${ }^{\mathrm{a}}$ Rabet Gozil ${ }^{\mathrm{a}}$ Engin Calguner ${ }^{\mathrm{a}}$ Meltem Bahcelioglu ${ }^{\mathrm{a}}$ \\ Serdar Mutlua ${ }^{a}$ Ayla Kurkcuoglu ${ }^{d}$ Deniz Yucel ${ }^{b}$ Eyup Senol ${ }^{e}$ Tevfik Babus ${ }^{c}$ \\ Dural Kadıoglu ${ }^{\mathrm{a}}$ \\ Departments of a Anatomy, ${ }^{b}$ General Surgery and ${ }^{c}$ Anesthesiology and Reanimation, School of Medicine, \\ University of Gazi, 'Department of Anatomy, School of Medicine, University of Baskent, and 'Department of Radiology, \\ Yuksek Ihtisas Hospital, Ankara, Turkey
}

\section{Key Words}

Horseshoe kidney $\cdot$ Renal vasculature $\cdot$ Upper urinary tract anomaly • Human horseshoe kidney

\begin{abstract}
Objective: To describe a horseshoe kidney, a congenital anomaly of the upper urinary tract. Clinical Presentation: A case study of horseshoe kidney harvested from a 62-yearold cadaver at Gazi University Medical School is presented. Results: The right and left kidneys were fused at their lower poles by a parenchymal isthmus located ventral to the abdominal aorta and formed a U-shape with two unequal arms. The isthmus of the ectopic kidney was placed obliquely to the left at the level of the fourth and fifth lumbar vertebra. The left kidney was larger and longer than the right one. The kidneys were supplied by three renal arteries arising from the abdominal aorta. Two arteries on the right side supplied blood of the two kidneys, while the third artery that directly originated from the aorta, above the origin of inferior mesenteric artery, supplied the isthmus. Venous drainage of the both kidneys and the isthmus were drained by three veins that opened independently into the inferior vena cava. The right ureter was duplicated in origin. Conclusion: This report shows that knowledge of anomalies such as this is very important in planning and conducting surgical procedures.

Copyright $\odot 2007$ S. Karger AG, Basel
\end{abstract}

\section{Introduction}

Berengario da Carpi was the first to mention the horseshoe kidney in 1552 and has recently been reported by others such as Chiche and Koskas [1]. Horseshoe kidney is a well-known congenital anomaly of the upper urinary tract [2]. The frequency of appearance is $1 / 400-800$ and it occurs more often in men $[2,3]$. In the horseshoe kidney there is a fusion of the lower poles of both kidneys. During migration from the sacral region the two metanephric blastemes can come into contact mainly at the lower pole. The bridge of parenchyma by which they are fused is called the isthmus. When the isthmus of a horseshoe kidney reaches the inferior mesenteric artery at the aorta, the kidneys can rise no further so this leads to a large U-shaped kidney [4].

This case describes in detail a urinary system anomaly in the form of a 'horseshoe kidney', the knowledge of which is required for radiological and operative procedures.

\section{Case Report}

During a routine abdominal dissection carried out in the Department of Anatomy, Gazi University Medical School, an anatomic specimen was harvested from a 62-year-old male patient. After removal of the perirenal fat, the horseshoe kidney and its

\section{KARGER}

Fax +41613061234 E-Mail karger@karger.ch www.karger.com (c) 2007 S. Karger AG, Basel

1011-7571/08/0171-0080\$24.50/0

Accessible online at:

www.karger.com/mpp
Meltem Bahcelioglu

Department of Anatomy, University of Gazi, School of Medicine

TR-06500 Besevler/Ankara (Turkey)

Tel. +90 31220246 18, Fax +90 3122124647

E-Mail meltemb@gazi.edu.tr or mbahcelioglu@gmail.com 
Fig. 1, 2. Photograph (1) and schematic illustration (2) of the horseshoe kidney. RK = Right kidney, LK = left kidney, $\mathrm{RU}=$ right ureter, $\mathrm{LU}=$ left ureter, $\mathrm{LCoV}=$ left colic vein, IMA = inferior mesenteric artery, $\mathrm{AA}=$ abdominal aorta, RCIA = right common iliac artery, LCIA = left common iliac artery, IsK = isthmus, TV = testicular vein, A1, A2, A3 = three renal arteries, IVC = inferior venae cavae, $\mathrm{V} 1=$ first vein, V2 = second vein, V3 = third vein.

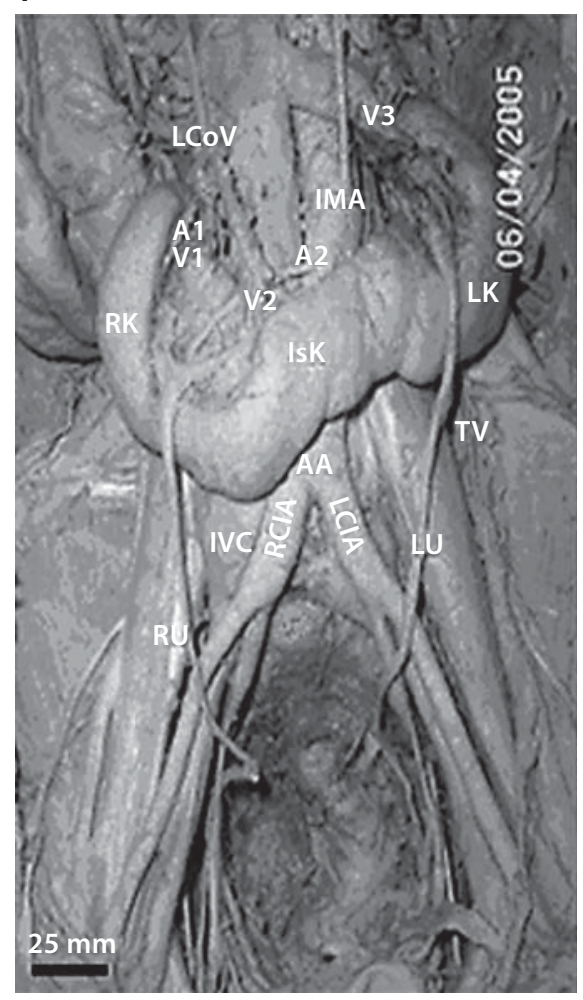

2

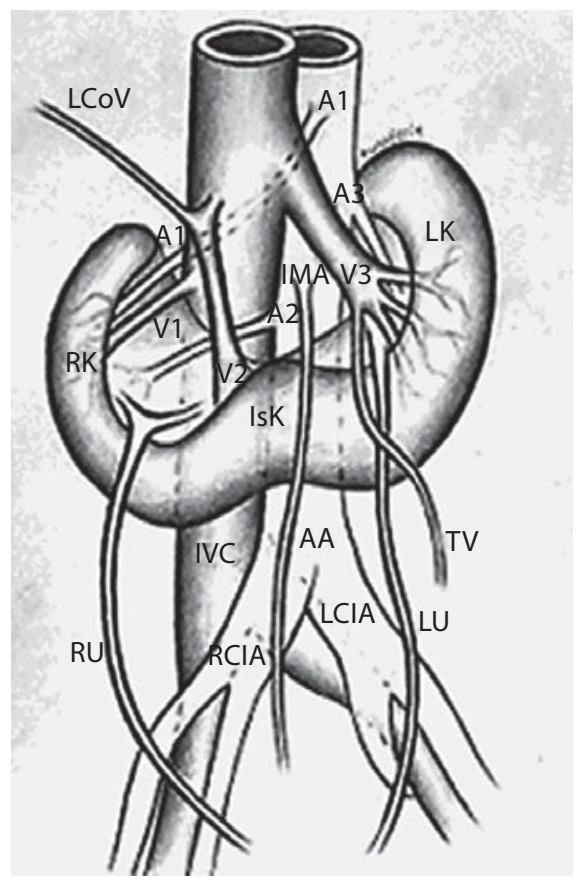

relation with the inferior vena cava and aorta were carefully examined. Its external appearance, dimensions and its blood supply were recorded as measurements, line drawings and photographs.

\section{Results}

The right and left kidney were fused at their lower poles by a parenchymal isthmus located ventral to the abdominal aorta and formed a U-shape with two unequal arms. The isthmus was oriented obliquely to the left (fig. 1, 2).

The total weight of the kidney was approximately $240 \mathrm{~g}$. The right kidney measured 101.27, 21.50 and 46.30 $\mathrm{mm}$ in length, width and thickness respectively. It was lying from the level between the L2 and L3 vertebras to the L5 vertebra corpus. The left kidney measured 107.37, 50.51, and $43.02 \mathrm{~mm}$ in length, width and thickness respectively. The superior pole was situated between the L1 and L2 vertebrae while the inferior pole at the level of L4 vertebra. The isthmus was positioned between the lower borders of the L4-L5 vertebra, which measured $43 \mathrm{~mm}$ in the long axis. The right renal hilum measured 55.48 and $36.23 \mathrm{~mm}$ in length and width respectively. The left renal hilum was oval in shape, and measured $31.44-21.55 \mathrm{~mm}$ (length-width). The left renal pelvis consisted of four major calyces and one of them originated from the isthmus. There were two main branches in the right renal pelvis which consisted of three major calyces.

The horseshoe kidney possessed three renal arteries (A1, A2, and A3). A1 (3.5 mm in diameter) originated from $10.88 \mathrm{~mm}$ above the inferior mesenteric artery (IMA) and supplied the renal hilum. A2 $(3.80 \mathrm{~mm}$ in diameter) originated from abdominal aorta $19.17 \mathrm{~mm}$ below the IMA and gave off a branch. A3 $(4.71 \mathrm{~mm}$ in diameter) supplied only the left kidney and originated from $26.07 \mathrm{~mm}$ above the IMA and gave off two branches to left renal hilum and kidney. The isthmus was supplied by the terminal branch of the A3.

The inferior vena cava (IVC) was $32.15 \mathrm{~mm}$ in diameter behind the isthmus and the lower pole of the right kidney. Three veins opened independently into the IVC. The first vein (V1) opened into the IVC at the level of L2L3 vertebrae. A vein emerging from the superior and anterosuperior segments of the right kidney and a second vein emerging from the anteroinferior segments are combined at the level of L3 vertebra to form V1. The second vein (V2) emerged from the inferior segment of the 


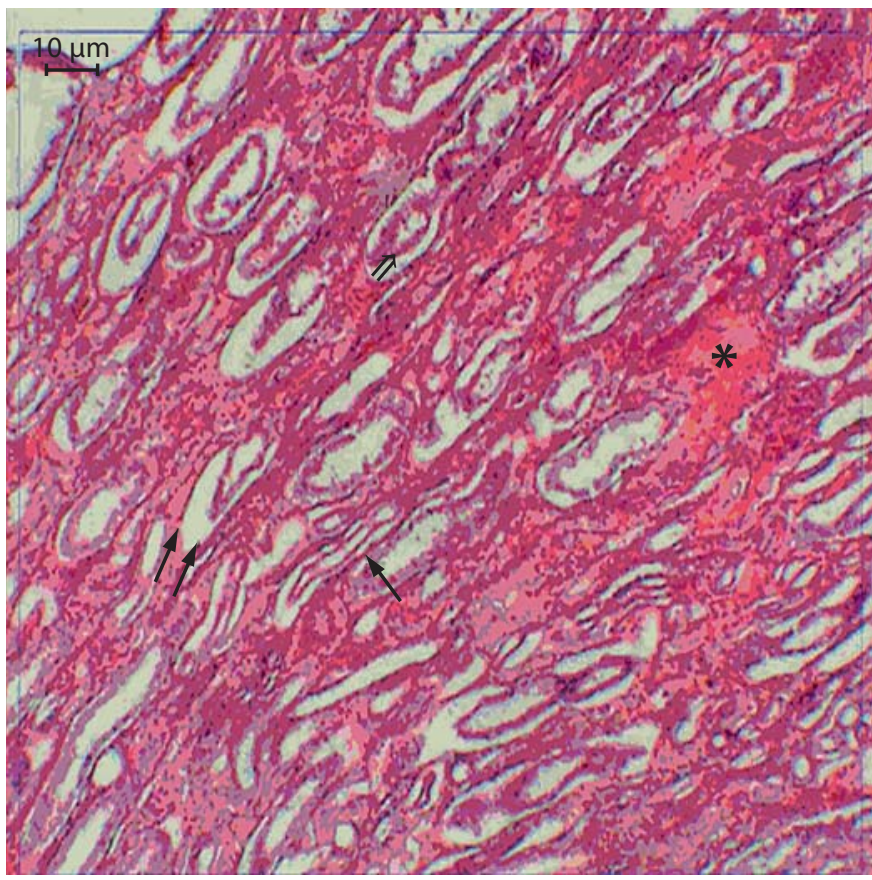

Fig. 3. Light microscopy of the isthmus. $\Uparrow=$ Collecting tubules, $\uparrow \uparrow=$ peritubular edema, $\uparrow=$ thin segment of the loop of Henle, * = interstitial tissue. HE.

right kidney. After the confluence of the left colic vein, it finally opened into the right ventral side of the IVC. The third vein (V3) (19.25 $\mathrm{mm}$ in diameter) was formed by the confluence of two veins. A ventral vein emerging from the superior, anterosuperior segments of the left kidney and a dorsal vein originated from the posterior, anteroinferior, inferior segments and isthmus. After the confluence at the level of L2-3, V3 ascended to the left side of the abdominal aorta and opened into the IVC (fig. 1, 2).

The right ureter had duplicated at the origin; the left branch was $4.48 \mathrm{~mm}$ in diameter and the right $6.66 \mathrm{~mm}$. After the confluence, the diameter of the right ureter was $3.84 \mathrm{~mm}$ and the left $3.60 \mathrm{~mm}$.

Light microscopic investigation of the isthmus revealed that the parenchyma was in the form of medullar kidney. The collecting tubules and thin segment of the loop of Henle were observed in the parenchymal area and also peritubular edema was significant in collecting tubules. The increase in medullar interstitium with fibrotic appearance was another significant result (fig. 3).

\section{Discussion}

Horseshoe kidney can be U-, horseshoe- or L-shaped. The morphologic appearance of horseshoe kidney is in direct relation with the manner of fusion of the two kidneys: fusion on the midline results in an approximately symmetric horseshoe, with the two kidneys symmetrically placed on the sides of the vertebral column, lateral fusion results in an asymmetric kidney with the isthmus placed lateral to the midline, and crossed renal ectopia. In our case, lateral asymmetrical fusion of the two kidneys was observed. The right and left kidneys were fused at their lower poles by a parenchymal isthmus located ventral to the abdominal aorta and formed a U-shape with two unequal arms. The isthmus was oriented obliquely to the left. The ventral side of the kidney was convex, whereas the dorsal side was slightly concave [3].

Usually, horseshoe kidney is located in a lower lumbar position, at the L3-L5 vertebral level, in front of the aorta and IVC and posterior to the IMA, which usually crosses the isthmus [5]. In our case, the right kidney was lying from the level between the L2 and L3 vertebra to the L5 vertebra corpus while the left kidney was situated between L1 and L2 vertebra to the L4 vertebra.

Horseshoe kidney is rarely associated with other vascular anomalies such as duplication of IVC, preisthmic IVC or persistent superior vena cava [6], as was not observed in our case.

It is well known that horseshoe kidney shows a wide variation of the arterial blood supply [2] as in this case where there were two arteries on the right side supplying blood to the two kidneys. The third one (A3) directly arose from the aorta above the origin of the IMA and supplied the isthmus. Venous drainage of both kidneys and the isthmus were taken by three veins that opened independently into the IVC.

Light microscopic results revealed that the isthmus was in the form of a medullary kidney with a fibrotic appearance of the interstitium, while Yoshinaga et al. [2] described a renal parenchymal structure with absent glomeruli in the left kidney with atrophic or greatly dilated urinary tubules [2]. Collecting tubules and a thin segment of the loop of Henle were observed in the parenchymal area with significant peritubular edema, while Yoshinaga et al. [2] reported urinary tubules lined by flattened epithelium, and filled with eosinophilic material [2]. Horseshoe kidney can be presented with rare ureter variations like circumcaval ureter and intercommunicating renal pelves drained by a single ureter [7]. In this study, the right ureter was duplicated at the origin; 
these two branches were united and continued as one at the right side of the isthmus. Witeska [8] reported that the existence of the horseshoe kidney may facilitate lesion of the renal parenchyma by creating urine stasis, infections, lithiasis and therefore surgical correction of this rare anomaly should aim at saving both the kidneys [8].

\section{Conclusion}

This case demonstrates that knowledge of such anomalies as described in this case is very important in planning and conducting surgical procedures.

\section{Acknowledgment}

The authors express their profound gratitude to their medical illustrator, Tuna Ferit Hidayetoglu, for his original artwork.

\section{References}

1 Chiche L, Koskas F: Aneurisme aortique ab dominal et rein en fer à cheval. Sang Thrombose Vaisseaux 2001;4:248-250 (cited in ref. 4).

2 Yoshinaga K, Kodama K, Tanii İ, Toshimori K: Morphological study of a horseshoe kidney with special reference to the vascular system. Anat Sci Int 2002;77:134-139.

3 Bordei P, Antohe DS, Iliescu D, Sapte E: 'Horseshoe kidney' in an ectopic position. A case report. Surg Radiol Anat 2003;25:345349 .
-4 Domenech-Mateu JM, Gonzalez-Compta X: Horseshoe kidney: a new theory on its embryogenesis based on the study of a $16-\mathrm{mm}$ human embryo. Anat Rec 1988;222:408417.

5 Moore KL: Clinically Oriented Anatomy, ed 3. Baltimore, Williams \& Wilkins, 1992 , p 223.
6 Smith TR, Frost A: Anomalous inferior vena cava associated with horseshoe kidneys. Clin Imaging 1996;20:276-278.

7 Knutson T, Hawas B: Horseshoe kidney with a circumcaval ureter. Scand J Urol Nephrol 2004;38:348-350.

8 Witeska A: Surgical treatment of patients with horseshoe kidney. Int Urol Nephrol 1982;14:349-352. 